\title{
Percepçôes do paciente oncológico sobre o cuidado
}

I ${ }^{1}$ Melina Raquel Theobald, ${ }^{2}$ Mara Lisiane de Moraes dos Santos,

${ }^{3}$ Sonia Maria Oliveira de Andrade, ${ }^{4}$ Alessandro Diogo de-Carli I

Resumo: O câncer desencadeia reações orgânicas e emocionais, provocando sentimentos, desequilíbrios e conflitos internos. O estudo procurou identificar as percepções do paciente oncológico sobre o cuidado profissional recebido. Trata-se de estudo qualitativo, constituindo-se como uma possibilidade de reflexão acerca da assistência prestada a estes pacientes, sob a ótica de uma abordagem humanística. Participaram da pesquisa 25 pacientes adultos internados no setor de Oncologia de uma instituição pública, de ensino e de referência na área, localizada na Região CentroOeste do Brasil, junto aos quais se realizou entrevista semiestruturada, que teve seu roteiro avaliado por profissionais da área temática. Após a coleta dos dados, estes foram transcritos e sistematizados pelo Discurso do Sujeito Coletivo, sendo posteriormente confrontados com o relatório da Observação Sistemática Participante. Como resultados, o estudo identificou percepção positiva do usuário sobre o cuidado recebido, embora a prática profissional incorpore parcialmente as recomendações preconizadas pela Política Nacional de Humanização. Concluiu-se que é necessário investir esforços no intuito de potencializar a incorporação de condutas profissionais que priorizem o cuidado humanizado, pois sua ausência compromete a adesão terapêutica, fragiliza o paciente, acarretando impactos emocionais no indivíduo.

\author{
1 Universidade Federal de Mato \\ Grosso do Sul, Mestrado em \\ Enfermagem. Campo Grande- \\ MS, Brasil (melinatheobald@ \\ hotmail.com). \\ ${ }^{2}$ Universidade Federal de \\ Mato Grosso do Sul. Campo \\ Grande-MS, Brasil (maralisi@ \\ globo.com). \\ ${ }^{3}$ Universidade Federal de Mato \\ Grosso do Sul, Doutorado em \\ Saúde e Desenvolvimento na \\ Região Centro-Oeste. Campo \\ Grande-MS, Brasil (soniaufms@ \\ gmail.com). \\ ${ }^{4}$ Universidade Federal de Mato \\ Grosso do Sul. Campo Grande- \\ MS, Brasil (alessandrodecarli@ \\ hotmail.com).
}


É inquestionável que o câncer é um problema de saúde pública, especialmente entre os países em desenvolvimento, onde se espera que, nas próximas décadas, seu impacto na população corresponda a 80\% dos mais de 20 milhões de casos novos estimados para 2025. A estimativa mundial, realizada em 2012, apontou que dos 14 milhões de casos novos estimados, mais de $60 \%$ ocorreram em países em desenvolvimento (BRASIL, 2015).

O câncer é uma doença com concepções criadas historicamente pela sociedade, como uma doença dolorosa e incurável (SILVA, 2005), sendo que seu diagnóstico desencadeia reações tanto no âmbito orgânico como no emocional, provocando sentimentos, desequilíbrios e conflitos internos, além de causar sofrimento que pode acarretar desorganização psíquica (SILVA, 2005; TAVARES, 2005).

Considerando as sérias repercussões que o câncer desencadeia, é crucial que a comunicação do profissional com o paciente ocorra de forma adequada. Nesse contexto, destaca-se o diálogo, que sempre foi fundamental nas relações humanas. Por meio dele, profissionais de saúde podem desenvolver uma escuta singular que permite apreender todas as demandas dos clientes. $\mathrm{Na}$ medida em que o diálogo avança, o vínculo profissional-paciente aparece, e deste nasce a confiança tão necessária na relação de ajuda (RENNÓ; CAMPOS, 2013; POTT et al., 2013).

Outro aspecto primordial para o paciente portador de câncer é o acesso às informações. Segundo Taddeo et al. (2012), a pessoa que está esclarecida e familiarizada com a condição de ter uma doença crônica e o fato de estar envolvida em seu tratamento, tende a se sentir mais segura e esperançosa quanto à evolução e prognóstico de sua doença. Contrário a isso, o não conhecimento acerca de sua doença leva os pacientes a não se comprometerem com o tratamento.

Não menos importante na cancerologia é o respeito à autonomia do indivíduo; logo, as relações de cuidado devem ser pautadas na convivência e interação saudáveis, e não em relações de domínio de uns sobre os outros. Para essa boa convivência, é imperativo que os profissionais de saúde modifiquem a forma de se posicionar diante da vida, dor e sofrimento do outro. No modelo humanista de assistência, os profissionais podem ouvir objetivamente o indivíduo, identificar suas necessidades e ajudar a encontrar soluçôes a partir do aumento das informações de sua própria atividade mental, instrumentalizando-o para o agir (RENNÓ; CAMPOS, 2013). 
Vale destacar que a comunicação, adequada informação e o respeito à autonomia são preceitos da humanização. Esta perpassa o respeito à individualidade da pessoa, ao mesmo tempo que suscita uma percepção holística desse ser, extrapolando a compreensão biologicista da doença e contemplando os aspectos psicológicos, sociais e espirituais que, direta ou indiretamente, influenciam a doença (FONTES; ALVIM, 2008).

Reconhecendo a importância de constante análise e reflexão sobre o cuidado prestado, especialmente na Oncologia, área que pode desencadear abalos emocionais e psicológicos, este estudo se propôs a verificar qual a percepção do usuário sobre o cuidado dos profissionais, no contexto da comunicação, da informação, da humanização e do respeito à autonomia. Objetivou-se compreender as percepçôes dos pacientes oncológicos acerca do seu cuidado; averiguar, junto aos pacientes, como ocorre a comunicação dos profissionais na realização do cuidado; identificar, pela ótica do paciente, como os profissionais realizam a informação do diagnóstico, tratamento e prognóstico da doença e identificar como os profissionais promovem o respeito à autonomia.

\section{Metodologia}

Trata-se de pesquisa qualitativa, exploratória, com fundamentação metodológica no Discurso do Sujeito Coletivo (DSC) e na Observação Sistemática Participante (OSP). A abordagem qualitativa do trabalho apresentou-se como suporte para a investigação, considerando que o estudo foi direcionado a um local com realidade complexa. Segundo Minayo (2007), a pesquisa qualitativa responde a questôes muito particulares e também se preocupa com aspectos que não podem ser quantificados.

O DSC é uma forma de organização e tabulação de dados qualitativos de natureza verbal, obtidos por meio de depoimentos, artigos de jornal, matérias de revistas, papers, entre outros. Para sistematizar e construir o DSC, foram utilizados trechos dos discursos que são reveladores da essência do conteúdo e, na metodologia, reconhecidos como Expressóes-chave (EC). A partir destas, foram identificadas as Ideias Centrais (IC), expressões linguísticas similares a categorias, que revelam de maneira sucinta o sentido presente nos depoimentos. Em posse das EC e das IC, os dados foram sistematizados e organizados nos mapas denominados "Instrumentos de Análise do Discurso" (IAD). Na ocorrência de 
1252 discursos contraditórios sobre a mesma questão, foram construídos DSC para as falas concordantes e discordantes (LEFÈVRE; LEFÈVRE, 2005).

Os dados primários foram obtidos por meio de entrevista semiestruturada, que foi aplicada nos pacientes internados na Oncologia de uma instituição pública vinculada ao SUS e de ensino. Tais dados foram confrontados com os obtidos por meio de uma OSP, pois, segundo Belei et al. (2008), abordar mais de um recurso permite novos caminhos, reforçando aspectos qualitativos da pesquisa, sem desconsiderar a fidedignidade.

Neste estudo, empregaram-se duas de fontes de dados (DSC/OSP), configurando um dos tipos de triangulação, recurso que objetiva enriquecer e complementar os resultados, superando os potenciais epistemológicos habitualmente limitados do método individual. A triangulação que pode se manifestar de diferentes formas não significa avaliar ou validar os resultados e procedimentos, mas ampliar e complementar sistematicamente as possibilidades de produção do conhecimento (FLICK, 2009).

Escolheu-se a entrevista como forma para obtenção destes dados porque tal estratégia possibilita que o indivíduo se expresse mais livremente, favorecendo a obtenção de um discurso. A "pergunta ideal" leva o entrevistado à produção de um discurso; o participante responde com exatidão aquilo que o pesquisador está investigando; o entrevistado responde o que ele acha e não o que o pesquisador pensa, é compreensível, clara e pré-testada (LEFÈVRE; LEFÈVRE, 2005).

Para assegurar que o instrumento fosse construído com a supracitada "pergunta ideal", alguns processos foram empregados. Primeiro, foi elaborado um instrumento relacionado diretamente com os objetivos do trabalho. Posteriormente, este foi encaminhado para análise de profissionais conhecedores do assunto e com experiência em pesquisa científica. Os juízes que participaram da avaliação semântica de conteúdo do instrumento foram: um cirurgiãodentista, três enfermeiros, duas psicólogas e duas médicas psiquiatras, todos com experiência na área.

Participaram da pesquisa os pacientes maiores de 18 anos, internados no setor de Oncologia adulto, e com adequado nível de consciência. Como o número de indivíduos neste setor é significativo, a seleção se fez considerando as características pessoais e ideológicas dos participantes, obtendo-se 25 participantes no estudo. Foram excluídos os indivíduos menores de 18 anos, os pacientes que apresentaram 
dificuldade de fala, compreensão, expressão, presença de desconforto (dor, náuseas, tontura, êmese).

Quanto aos aspectos éticos, o estudo foi aprovado pelo Comitê de Ética em Pesquisa com Seres Humanos da Universidade Federal de Mato Grosso do Sul, sob o protocolo número 890.370 , de 27 de novembro de 2014 .

\section{Resultados e discussão}

No intuito de conhecer como é a prática dos profissionais relativa ao cuidado dos pacientes com câncer e verificar se estas promovem um cuidado humanizado, apresentamos os resultados deste estudo em eixos temáticos, que são premissas para um cuidado qualificado. Estes foram representados da seguinte maneira: Comunicação, Informação, Autonomia e Percepção do cuidado.

\section{Comunicação}

No contexto da comunicação, foi possível obter dois DSC antagônicos. No primeiro, que teve como IC a "Comunicação Adequada", foi possível identificar a manifestação de uma boa comunicação no cenário explorado, conforme se evidencia a seguir:

A comunicação aqui é boa. Quando eu descobri a doença a médica conversou muito comigo, me acalmou e me apoiou. Quando converso com ela, eu fico melhor. E o bom é que eles sempre informam tudo o que estão realizando, são francos e honestos comigo (P1, P2, P9, P10, P14, P18, P20, P21, P19).

Foi possível identificar os aspectos positivos que uma comunicação adequada pode promover, visto que, além de aliviar os sintomas, acalmar e trazer o conforto, é elemento fundamental para o profissional da saúde, que busca uma assistência humanizada e que tem o cliente como centro de suas atenções, minimizando a despersonificação do indivíduo frente à hospitalização (FONTES; ALVIM, 2008; RENNÓ; CAMPOS, 2013).

Analisando esse discurso no trecho "[...] quando eu descobri a doença a médica conversou muito comigo, me acalmou e me apoiou [...]", percebe-se que a profissional trabalhou adequadamente a fase Emotions, apresentada por Buckman (1992), na qual se exploram as reações emocionais do paciente por meio de postura empática, além de demonstrar respeito ao usuário e favorecimento do estabelecimento de relacionamento efetivo com o indivíduo (OLIVEIRA et al., 2006; POTT et al., 2013; RENNÓ; CAMPOS, 2013). 
Nesse discurso, observamos que o profissional deu ênfase às tecnologias leves de cuidado, e estas trouxeram boas reações nos indivíduos. Como se verifica em "[...] quando converso com ela eu fico melhor [...]", constatamos que é possível evidenciar os benefícios de um cuidado subsidiado pelas tecnologias leves. Estas constituem o núcleo das tecnologias no trabalho vivo, a base do cuidado, o modo de trabalhar o campo relacional (acolhimento, vínculo) e as formas de gestão criativas que ajudam a fomentar a autonomia do sujeito em relação ao contexto de sua saúde (MERHY, 2007). Vale ainda destacar que, em muitos momentos, a palavra promove efeitos tão ou mais positivos quanto à administração de medicamentos, pois como se evidencia no trecho acima, a conversa pode promover a melhora dos indivíduos.

Com vistas ao discurso anterior, outro aspecto tem grande relevância, a valorização dos usuários quanto à sinceridade do profissional, como se pode evidenciar em "[...] o bom é que eles sempre informam tudo o que estão realizando, são francos e honestos comigo [...]". Considerando esta informação, nota-se que os trabalhadores são verdadeiros e honestos com os pacientes, e tal posicionamento favorece a relação de confiança que é essencial no cuidado. Entretanto, situação contrária foi encontrada por Gomes, Silva e Mota (2009), quando obtiveram um índice de omissão de diagnóstico de 28,5\%. A omissão é maior por médicos não especialistas, pois $87,9 \%$ deixaram de informar adequadamente seus pacientes, enquanto que para os médicos especialistas a omissão foi menor $(6,4 \%)$, mas ainda presente.

Ainda explorando o eixo temático da comunicação, foi identificado outro DSC que teve como ideia central a "Comunicação imprópria" e pode ser visualizado a seguir:

Eu acho que eles são secos, estúpidos e falam muito pouco. Chegam fazendo e não dizem nada e quando falam é muito difícil e a gente não entende. A comunicação tem que melhorar, a enfermeira fica falando dos outros pacientes e outro dia o médico tava falando com os alunos de mim no corredor e eu escutando daqui. (P1, P3, P11, P14, P17, P25).

Nesse alinhamento, identificamos inadequações em diferentes aspectos, como: postura desrespeitosa dos profissionais, emprego de termos que são incompreensíveis pelo usuário e falhas éticas. Tal fato indica um posicionamento profissional que compromete o cuidado, e que, em relação ao quesito 
"comunicação", promove a persistência de problemas na relação profissionalpaciente, em especial em situações que envolvem o câncer (PRIMO; GARRAFA, 2010), tendo em vista o cenário de incertezas e sofrimento comum nesses casos.

O posicionamento do profissional envolvido nesse discurso mostra a valorização dos procedimentos e a não utilização das tecnologias leves para o cuidado. Logo, tal encontro possivelmente produzirá sofrimento adicional ao paciente, sofrimento este que não tem a ver com a doença, mas com o cuidado. Neste cenário, Franco e Merhy (2013) salientaram que práticas fundamentadas em saberes técnicos onipotentes são pouco eficazes na satisfação das necessidades do usuário.

Sabendo que a informação favorece o exercício da autonomia e promove segurança ao indivíduo, é essencial que os profissionais se preocupem com a compreensão do usuário acerca das informações fornecidas. É conveniente que o trabalhador oportunize um momento para os questionamentos do usuário e também que se certifique se as informaçóes foram adequadamente compreendidas. É provável que a falta de entendimento desses usuários ocorra pelo posicionamento do profissional, que não verifica o grau de entendimento das informações transmitidas. Caprara e Rodrigues (2004) constataram que $39,1 \%$ dos médicos não explicavam de forma clara e compreensiva o problema, e em $58 \%$ das consultas o médico não verificava o grau de entendimento do paciente sobre o diagnóstico; em $53 \%$ das situações, não havia verificação da compreensão sobre as indicações terapêuticas.

Ainda considerando este DSC, na seguinte fala: “[...] chegam fazendo e não dizem nada [...]", fica clara a falta de comunicação, que implica falha ética do trabalhador. A ausência de comunicação, em suas distintas formas, durante as ações do cuidado, remete a um dilema ético/moral no qual se negligencia a dimensão psicoespiritual e social do indivíduo cuidado, que mesmo muitas vezes impossibilitado de se expressar, ainda possui suas peculiaridades, seus medos e anseios (POTT et al., 2013).

Neste DSC, outro aspecto que merece atenção é o que está exposto no trecho "[...] outro dia o médico estava falando com os alunos de mim no corredor e eu escutando daqui [...]". Infelizmente, ainda são comuns situações dessa natureza em serviços que atuam como espaços de formação na saúde. Refletem a ausência do debate da importância da utilização das tecnologias leves, do respeito ao usuário e da preocupação com o outro durante a formação dos profissionais de 
saúde. Tais práticas são preocupantes, uma vez que podem ser perpetuadas pelos profissionais que estão em formação.

No intuito de assegurar maior confiabilidade aos achados, os dois discursos antagônicos do eixo temático da comunicação foram confrontados com os dados obtidos através da OSP:

\begin{abstract}
Quanto à comunicação relacionada à socialização/educação dos profissionais para com os pacientes, foi possível observar o predomínio de postura positiva, visto que a maioria dos profissionais adentra na enfermaria com bom-humor, educação, cumprimentando os pacientes, perguntando como estão se sentindo. Em alguns casos, quanto houve alguma reclamação ou reinvindicação do usuário para com relação à equipe, identificou-se claro ressentimento desta e subsequentemente prejuízo nesta categoria de comunicação. Os pacientes internados neste setor têm oscilação do humor e frequentemente ficam calados e pouco comunicativos. Diante destas manifestaçôes, habitualmente os profissionais não entendem e reclamam da postura do paciente, mas como o "canal" da comunicação está "fechado" por parte do paciente, os profissionais, minimizam a comunicação (OSP).
\end{abstract}

Observando o trecho desta OSP, percebe-se que a equipe não recebe bem as críticas que emergem dos pacientes, fica ressentida com o usuário e muda seu relacionamento com o mesmo, comprometendo a comunicação relativa à sociabilização. Neste sentido, percebe-se que a equipe incorporou a postura paternalista mencionada por Miranda (2000), como única detentora de poder e conhecimento, subestimando a capacidade do paciente em fazer julgamentos.

$\mathrm{O}$ fato de que os pacientes "[...] frequentemente ficam calados e pouco comunicativos. Diante destas manifestações, habitualmente os profissionais não entendem e reclamam da postura do paciente [...]" revela que alguns aspectos permaneceram ocultos nos DSC dessa temática, tendo em vista que o relatório expôs como a postura de um dos membros envolvidos na comunicação pode influenciar negativamente na relação entre os indivíduos. Esta realidade é comum nos ambientes hospitalares, especialmente nos setores de cuidado oncológico, e pode ser potencializada pela manifestação de um "ruído" na comunicação, representado pela alteração de humor e/ou ocorrência anterior de algum atrito com o trabalhador (RENNÓ; CAMPOS, 2013). Por outro lado, se "[...] Os pacientes internados neste setor têm oscilação do humor e frequentemente ficam calados [...] os profissionais reagem respeitando o momento do indivíduo, minimizando a comunicação", percebe-se que houve modificação na postura do profissional para com o usuário, corroborando aspectos mencionados por Costa 
(2004), que destacou que a capacidade da comunicação influencia e afeta o comportamento das pessoas.

Considerando o trecho inicial do relatório, em que "[...] a maioria dos profissionais adentra na enfermaria com bom-humor, educação, cumprimentado os pacientes, perguntando como estão se sentindo [...]", nota-se que os profissionais adotaram uma estratégia que estimula a relação interpessoal. Vale destacar que algumas estratégias, como escuta atentiva, sorriso que expresse confiança, toque carinhoso que proporcione apoio e conforto, favorecem a relação interpessoal (OLIVEIRA et al., 2006).

Ainda com vistas ao que foi obtido por meio da OSP:

Quanto à comunicação relacionada à administração de medicação, é possível visualizar predominantemente prejuízo da comunicação, pois os profissionais rotineiramente não informam o fármaco que estão ministrando. Habitualmente, quando não ocorre contato entre os envolvidos, a comunicação é inadequada. Alguns funcionários até expõem que só informam o que estão ministrando diante do questionamento por parte do paciente. Já a comunicação que antecede o toque entre os indivíduos, na realização de procedimentos frequentemente é feita de forma adequada (OSP).

Verificamos que a comunicação que antecede a realização dos procedimentos comumente é adequada somente quando envolve o toque, e inadequada no momento da administração dos fármacos. Isto compromete a relação de confiança tão necessária na relação de ajuda (OLIVEIRA et al., 2006; RENNÓ; CAMPOS, 2013).

O relatório proveniente da OSP também traz importantes aspectos no que tange à comunicação de informações sobre a doença, tratamento e prognóstico:

Quanto à comunicação relacionada à informação da doença, tratamento e prognóstico, percebe-se que existe aparente relação com questôes culturais e sociais. Pacientes com baixo nível social são frequentemente pouco informados, estes habitualmente não apresentam questionamento algum e subsequentemente não ocorre estímulo/ motivação da comunicação neste aspecto. De forma contrária, os pacientes com melhor nível social e cultural são esclarecidos de forma mais atenciosa por parte dos profissionais (OSP).

Embora o instrumento da OSP não tenha contemplado a verificação do nível social e cultural, mas, sendo a OSP um procedimento observacional e, portanto, dependente do "olhar" do observador, julgamos pertinente problematizar esta questão. Dessa forma, a OSP, ao potencializar a possibilidade de ampliar os resultados da pesquisa, complementando a coleta de dados junto ao cenário/ 
sujeitos da pesquisa, foi capaz de desvelar aspectos que não foram mencionados nos discursos, como a relação do nível social e cultural com a comunicação.

Assim, há que se considerar a possibilidade de que tal achado indique que os aspectos culturais e socioeconômicos influenciam a comunicação. Nesse contexto, o baixo nível de compreensão, interferência da doença, o estado emocional e o receio de perguntas não podem justificar que o direito do paciente quanto às informações seja tolhido, sendo dever do profissional reconhecer o direito do paciente de saber seu prognóstico, diagnóstico e tratamento de maneira clara e verdadeira (ZABOLI; SARTORIO, 2006). Ademais, o não conhecimento acerca de doença pode levar os pacientes a não se comprometerem com o tratamento (OLIVEIRA et al., 2006; TADDEO et al., 2012).

\section{Informação}

Seguindo com o segundo eixo temático, que versa sobre a informação acerca do diagnóstico, tratamento e prognóstico, este estudo obteve dois DSC com ideias distintas; o primeiro, que teve como IC a "Informação Adequada", apresenta-se a seguir:

Eu sei de todo o tratamento, me explicaram tudo certinho: riscos, reações e que iria deprimir o meu sistema imunológico. Fui informada logo no início, ela olha no meu olho e não consegue mentir, não fiquei com dúvida, pois foram bem claros e precisos comigo (P2, P3, P6, P9, P10, P11, P14, P17, P24).

O discurso apresenta a satisfação dos usuários, visto que foram informados adequadamente sobre sua patologia. Brandão, Giovanella e Campos (2013) identificaram a satisfação dos participantes com a explicação dos profissionais sobre seus exames (38\%), e 37\% responderam "muito bom" sobre as informaçôes recebidas acerca dos sintomas da doença.

A postura dos profissionais, observada no referido DSC, demonstra o respeito aos direitos dos pacientes, os quais poderão exercer sua autonomia de forma consciente e com adequado nível de esclarecimento. Nesse cenário, a maioria dos pacientes deseja saber a verdade e pode participar das escolhas sobre sua própria saúde (SILVA et al., 2003; MIYATA et al., 2005).

Ainda analisando este discurso, por meio da observação do trecho "[...] ela olha no meu olho e não consegue mentir [...]", destaca-se a relação de vínculo entre profissional e paciente, que no contexto terapêutico pode influenciar tanto no desenvolvimento quanto na qualidade no tratamento (RENNÓ; CAMPOS, 2013). 
No quesito "Informação", foi possível observar também um discurso antagônico, que teve como ideia central "Informação Inadequada":

Fiquei sabendo que eu tinha leucemia no transporte do SAMU, dentro da ambulância. Só falaram que iam me internar e não falaram as coisas, o que sei é dos outros pacientes, ou por que eu pesquisei. Não sei o que está acontecendo, estamos na expectativa e assustados. Sou informada depois que as coisas acontecem (P1, P2, P3, P4, P8, P11, P12, P13, P15, P19).

Analisando este DSC, constatamos que o tratamento não foi discutido com o paciente, desrespeitando-se a fase Strategy and summary que é recomendada pelo protocolo de Spikes (BAILE et al., 2000). Segundo os autores, nesta fase, que representa o sexto e último passo do protocolo, o profissional deveria discutir as possibilidades terapêuticas e o prognóstico, apresentando também as possibilidades de falhas terapêuticas ou efeitos adversos, alimentando expectativas reais e considerando a autonomia do paciente na escolha do tratamento.

Dessa forma, fica nítido que a informação acerca da doença não foi planejada e ocorreu em local impróprio, fato que evidencia o descumprimento da segunda fase do referido protocolo, denominada Setting up, que consiste na preparação da entrevista com escolha de local adequado e a forma como será apresentada a notícia ao paciente (BAILE et al., 2000).

Em relação à informação, segue o trecho do relatório proveniente da OSP:

A informação do diagnóstico, tratamento e prognóstico ocorre de forma limitada;
habitualmente os pacientes que estão mais informados são os que apresentam melhor
nível cultural, social. Nota-se que os profissionais passam a visita e realizam os cui-
dados com bastante pressa, possivelmente em virtude de sobrecarga de trabalho na
própria instituição ou por terem outros compromissos em outros espaços de trabalho,
comprometendo este item, pois o tempo necessário para promover adequada infor-
mação é significativo. Outro aspecto evidente é o receio dos usuários em questiona-
rem os profissionais médicos. Os médicos são os principais envolvidos na transmissão
das informações e os profissionais da enfermagem são os que são procurados para
esclarecimentos e retirar as dúvidas. Também é evidente que a informação é apresen-
tada de forma parcial, visto que, existem muitas dúvidas (OSP).

Assim sendo, novamente verificamos a interferência do nível social e cultural na postura do profissional quanto à disponibilização adequada das informações, pois a informação aos indivíduos menos esclarecidos é mais difícil de ser realizada (SILVA et al., 2003). Entretanto, não é aceitável infringir o direito do paciente quanto à informação (ZABOLI; SARTORIO, 2006). Possivelmente, a existência das dúvidas, mesmo após as informações, tenha relação com a afirmação de 
Silva et al. (2003), que salientaram as diferenças entre informar diagnóstico e discutir prognóstico. Neste sentido, os médicos norte-americanos experimentam dificuldade com relação a dar informações acerca do prognóstico.

Outro aspecto que foi constatado no relatório da OSP, sobre informação, foi a maior liberdade do usuário com os profissionais da área da enfermagem para retirar as dúvidas, o que sugere uma relação profissional-paciente mais técnica com os médicos e mais afetiva com os profissionais da enfermagem (RENNÓ; CAMPOS, 2013).

\section{Autonomia}

O conhecimento e o acesso às informações sobre sua doença são imprescindíveis para a realização de escolhas e o exercício da autonomia; entretanto, a ausência de conhecimento pode levar os pacientes a não se comprometerem com seu tratamento (SOARES, 2000; TADDEO et al., 2012; GUEDES; HENRIQUE; LIMA, 2013). Seguem os DSC obtidos acerca desta temática, sendo que o primeiro foi construído com a IC "Participação no tratamento":

Eu me envolvo bastante. Às vezes eu acho que até incomodo um pouco. A dieta mesmo eu interfiro bastante e outro dia eu falei que não queria que pegasse veia no meu pescoço e eles concordaram e também eu pedi pra sair que tinha que ir ao INSS e eles me liberaram (P1, P2, P6, P9, P12, P14, P15, P18).

Com a observação deste DSC, foi possível identificar um posicionamento que favorece o exercício da autonomia e vai ao encontro da afirmação de Silva (2010), que confere ao indivíduo autônomo o respeito pelo direito de autogoverno, de tomar as decisōes relacionadas com sua vida, sua saúde, sua integridade físicopsíquica e suas relaçôes sociais. Considerando que o respeito aos direitos do paciente vai além do conhecimento técnico-científico, mensurável e hipocrático, foi possível detectar aqui uma prática fundamentada no conhecimento estético e ético (CAMACHO, 2002).

Com essa postura, é possível que os profissionais responsáveis pelo cuidado tenham reconhecido o indivíduo como autônomo, multidimensional, com suas especificidades e que vivencia um momento atípico e frágil de sua vida. No discurso exposto, o perfil paternalista e hipocrático (CAMACHO, 2002; TRINDADE et al., 2007) enraizado no pensar e agir do profissional de saúde ficou ausente, demonstrando que talvez, nesse sentido, a prática profissional esteja 
contemplando aspectos importantes relativos ao respeito ao usuário, para além de ações prescritivas, autoritárias e que desconsideram as necessidades do paciente.

De forma oposta, no segundo discurso sobre a temática, que teve como ideia central "Imposição", ficou evidente o desrespeito ao princípio da autonomia:

Muitas vezes eu não quis fazer a quimioterapia, mas a doutora me convenceu, disse que eu tinha que seguir o protocolo. $\mathrm{O}$ tratamento não foi explicado para mim, não tive muita escolha, as coisas vão acontecendo e depois que eu fico sabendo (P3, P13, P14, P15, P18, P20, P25).

Com essas falas, demonstra-se prejuízo ao exercício da autonomia em virtude de posturas que priorizam ações respaldadas em protocolo, consolidando o fato de que, não raramente, o cumprimento de rotinas obscurece a dimensão singular do paciente e é um desrespeito a seus direitos (SILVA; SÁ; MIRANDA, 2013). Além disso, fica clara a relação de poder ainda presente na relação profissionalpaciente, quando esta deveria ser pautada na convivência/interação saudáveis, e não em relações de domínio de uns sobre os outros (TORALLES-PEREIRA et al., 2009; RENNÓ; CAMPOS, 2013).

Refletindo sobre uma maneira de modificar esse posicionamento, que compromete o exercício da autonomia, destacamos a necessidade de mudar a prática profissional. Explorando esse processo de mudança, é oportuno analisar o raciocínio de Franco e Merhy (2013) sobre a questão. Segundo os autores, a mudança pressupõe a desterritorialização, ou seja, a ruptura com o velho território e o movimento de reterritorialização, buscando novas identidades existenciais que vão pedir novas práticas de cuidado. Ainda considerando as possibilidades que podem favorecer as mudanças e, subsequentemente, diminuir as agressões na autonomia do usuário, vale considerar o desejo, que é a força motriz de construção da sociedade. $\mathrm{O}$ desejo é revolucionário, como produção, tem a energia para a invenção da realidade social e a criação de um novo devir para o mundo da vida (FRANCO; MERHY, 2013).

Em contrapartida, ainda na temática que explora a autonomia, este estudo obteve um terceiro discurso, que teve como ideia central "Confiança no profissional":

Eles que estão sabendo o que estão fazendo, pois eles é que estudaram e eu não posso interferir; eles até me escutam, mas é eles que decidem de fato. Também não quero ultrapassar o limite profissional, pois acho que é só a médica que tem que decidir estas coisas e a gente tem que fazer o que eles dizem, pois é por causa dela que eu estou viva ainda (P3, P7, P11, P17, P18, P21, P23). 
Nesse discurso, revelou-se o exercício da autonomia de forma peculiar, em que os participantes manifestaram o desejo de não interferir. Houve uma manifestação consciente e autônoma fundamentada na confiança pelo profissional, possivelmente desvinculada do conceito de independência absoluta, habitualmente preconizado, considerando-se que o indivíduo se torna autônomo a partir da relação que estabelece com o outro (ONOCKO; CAMPOS, 2006), que neste caso foi à relação de confiança. Dessa maneira, os autores afirmaram que os graus de autonomia dependem do modo de funcionamento das organizações de saúde, dos valores que lá são veiculados e também da cultura em que o sujeito está inserido.

No cenário da autonomia, o relatório de OSP reforça achado do segundo DSC desta temática, conforme observado a seguir:

\footnotetext{
Neste serviço, não ocorre estímulo ao empoderamento dos pacientes, visto que estes não têm espaço para se manifestarem. Os profissionais apresentam as possibilidades terapêuticas já com discurso de convencimento que enfatiza a importância de seguir o protocolo para assegurar a cura da doença. Também não é evidente o estímulo à apresentação das dúvidas do usuário (OSP).
}

Esta constatação corrobora o fato de que os profissionais de saúde não reconhecem os pacientes como capazes de realizar seu próprio cuidado, e assim deixam de orientá-los, informá-los e de realizar práticas de educação em saúde (TADDEO et al., 2012). Isso pode ser observado na postura autossuficiente do profissional, na valorização de protocolos e desqualificação do outro (BIRMAN, 2010).

Considerando que o Ministério da Saúde preconiza na Política Nacional de Humanização $(\mathrm{PNH})$ o incentivo à autonomia e o protagonismo dos indivíduos (BRASIL, 2004), salienta-se que, no cenário estudado, os profissionais não incorporaram integralmente os preceitos da referida política. Tal fato pode estar repercutindo negativamente na adesão ao tratamento e implicando inexistência de espaço e oportunidade para a manifestação do usuário (TADDEO et al., 2012).

\section{Percepção do cuidado}

Para compreender a opinião dos sujeitos sobre o cuidado, obtivemos a quarta temática explorada neste estudo, que é a "Percepção sobre o cuidado recebido", em que emergiram dois DSC, que representam visões positivas quanto ao aspecto analisado. O primeiro discurso foi construído a partir da ideia central "Competência": 
Esse discurso demostra a valorização que o paciente dá ao conhecimento técnico e aos procedimentos. Embora a pergunta, na entrevista, faça referência aos cuidados, eles remetem à competência para realizar procedimentos técnicos. Identificamos o reconhecimento dos usuários quanto à capacidade técnica dos trabalhadores, que vai ao encontro dos pressupostos do cuidado humanizado quando contempla a importância das ações de eficiência técnica e científica, em consonância com a postura ética (BARBOSA et al., 2013). Esta última não foi evidenciada neste discurso. Embora os sujeitos da pesquisa tenham valorizado a competência técnica, é válido destacar que o cuidado à saúde transcende o simples agir fundamentado na capacidade técnica, centrado no fazer ou nos procedimentos.

Com vistas ao DSC supracitado, verificamos que existe predomínio da valorização das tecnologias leve-duras, que são os saberes estruturados que fundamentam a operacionalização do cuidado (MERHY, 2007). Entretanto, não foi possível identificar a manifestação dos usuários reconhecendo as tecnologias leves como parte do cuidado recebido, embora nos discursos anteriores tal reconhecimento tenha ficado evidente. As tecnologias leves do cuidado são essenciais na construção de vínculo, têm relação com o posicionamento ético do profissional e não podem ser desconsideradas no exercício do cuidado (MERHY, 2007).

Mesmo verificando uma percepção positiva por parte usuário ao ser questionado sobre o cuidado recebido, a referência desses participantes apenas à capacidade técnica pode sugerir que nesse local predomina o modelo flexneriano. Isso contraria o pressuposto de que o cuidado deve extrapolar a compreensão biologicista da doença e contemplar também os aspectos psicológicos, sociais e espirituais que, direta ou indiretamente, influenciam o processo saúde-doença (PESSINI, 2004; FURNARI, 2005; FONTES; ALVIN, 2008).

No âmbito da percepção do cuidado, obtivemos um segundo DSC, que teve como IC a "Satisfação":

Eles tratam muito bem a gente, são muito bons, não tenho do que reclamar, não me tratam com indiferença e são carinhosos (P2, P3, P6, P8, P9, P12, P13, P16, P17, P20, P22). 
Considerando a satisfação dos usuários, os achados oriundos deste DSC corroboram os demonstrados por Brandão, Giovanella e Campos (2013), que avaliaram a atenção básica pela perspectiva dos usuários. Os autores encontraram resultados positivos acerca da prática dos profissionais de saúde e elevada satisfação dos usuários, situação contraposta à existência de queixas de maustratos, desrespeito e falta de humanidade (GUEDES; HENRIQUE; LIMA, 2013). Neste DSC, a manifestação de carinho por parte dos profissionais denota possivelmente o estabelecimento de uma relação ou vínculo que deve ser o eixo norteador do cuidado em saúde, cuja qualidade depende das relações que são desenvolvidas e fortalecidas entre profissionais e usuários, verdadeiros parceiros na busca pela promoção da saúde (GUEDES; HENRIQUE; LIMA, 2013).

Prosseguindo com os achados, o relatório proveniente da OSP traz informações que reforçam os aspectos identificados nos DSC desta temática, conforme pode ser analisado a seguir:

Os pacientes têm uma visão positiva do cuidado recebido. As poucas manifestaçôes de insatisfação têm variações de acordo com a categoria profissional. Neste contexto, o profissional médico recebe do paciente parecer de qualidade e satisfação do usuário, ao passo que no cenário da enfermagem, mesmo aparecendo de forma esporádica é possível identificar manifestações de insatisfação quanto ao cuidado recebido (OSP).

Mesmo que de forma tímida, a insatisfação para com a categoria da enfermagem expõe a existência de grande lacuna do que é proposto pelas políticas públicas e o que os que executam a política em seu dia a dia podem realizar (SILVA; SÁ; MIRANDA, 2013; GUEDES; HENRIQUE; LIMA, 2013). Isso pode ser explicado pelo fato de que os profissionais da enfermagem detêm grandes cargas de trabalho e, assim, apresentam dificuldade em viabilizar um atendimento diferenciado em função da grande demanda de serviço (GUEDES; HENRIQUE; LIMA, 2013).

Considerando que as ações de cuidado em saúde envolvem a comunicação e a adequada informação, que subsidia e favorece a manifestação da autonomia, foi possível constatar que os profissionais atuantes no cenário de práticas em questão incorporaram parcialmente tais premissas em sua prática. Com exceção da percepção geral do cuidado, que obteve apenas manifestações positivas, nos demais aspectos analisados no presente estudo, identificamos um perfil discursivo caracterizado pela presença de contraposiçôes, as quais puderam ser mais bem entendidas pela OSP. 
Refletindo sobre os aspectos que emergiram neste estudo, constatamos que os usuários atribuíram valor às tecnologias leves e às leves-duras. Embora haja evidências consistentes de que as tecnologias leves, comunicação adequada, informação e autonomia repercutem nos resultados terapêuticos, além de perpassarem pelos direitos dos pacientes e da ética dos profissionais, estes aspectos ainda configuram importantes lacunas na produção do cuidado no cenário analisado.

\section{Conclusões}

Os achados do presente estudo demonstram que, do ponto de vista dos usuários e corroborado pela OSP, o cuidado em seu sentido mais amplo ainda não é incorporado plenamente no cenário explorado. A comunicação, o fornecimento da informação e o estímulo à autonomia são exercidos adequadamente em alguns momentos no setor estudado; no entanto, ainda se evidenciam lacunas importantes em relação a tais aspectos nas práticas dos profissionais desta instituição de atenção oncológica.

$\mathrm{Na}$ perspectiva do usuário, evidenciou-se que as questôes relativas à informação sobre diagnóstico, tratamento e prognóstico nem sempre foram adequadamente discutidas, o que implica, também, desconsideração sobre a autonomia do paciente.

Todas as temáticas exploradas na presente pesquisa estão interligadas e subsidiam o cuidado. Logo, pelos achados aqui evidenciados, salienta-se a necessidade de que os profissionais reflitam sobre suas práticas cuidadoras e seu papel enquanto trabalhadores da saúde. Mesmo na oncologia, onde as repercussões emocionais são importantes e de grande impacto, o cuidado ainda se apresenta de forma inadequada em determinados momentos.

É essencial superar as lacunas que interferem negativamente no cuidado, pois, além dos conhecimentos técnicos e recursos de densidade tecnológica necessários ao cuidado à pessoa com câncer, posturas profissionais mais acolhedoras e cuidadoras são imprescindíveis e de grande repercussão terapêutica, bem como a responsabilização individual de cada profissional da saúde para com o ser humano. ${ }^{1}$

\section{Referências}

BARBOSA, G. C. et al. Política Nacional de Humanização e formação dos profissionais de saúde: revisão integrativa. Revista Brasileira de Enfermagem, v. 66, n. 1, p. 123-127, 2013. 
BELEI, R. A. et al. O uso da entrevista, observação e videogravação em pesquisa qualitativa. Cadernos de Educação, v. 30, p. 187-199, 2008.

BIRMAN, J. Governabilidade, força e submissão: Freud e a filosofia política. Psicologia USP, v. 21, n. 3, p. 531-556, 2010.

BRANDĀO, A. L. R. B. S.; GIOVANELLA, L.; CAMPOS, C. E. A. Avaliação da atenção básica pela perspectiva dos usuários: adaptação do instrumento EUROPEP para grandes centros urbanos brasileiros. Ciência \& Saúde Coletiva, v. 18, n. 1, p. 103-114, 2013.

BRASIL. Ministério da Saúde. Instituto Nacional de Câncer José Alencar Gomes da Silva. 2016: incidência de câncer no Brasil. Rio de Janeiro: INCA, 2015.

BAILE, W. F. et al. A six-step protocol for delivering bad news: application to the patient with cancer. The Oncologist, v. 5, p. 302-311. 2000.

CAMACHO, A. C. L. F. A gerontologia e a interdisciplinaridade: aspectos relevantes para a enfermagem. Revista Latino Americana de Enfermagem, v. 10, n. 2, p. 229-233, 2002.

CAPRARA, A.; RODRIGUES, J. A relação assimétrica médico paciente: repensando o vinculo terapêutico. Ciência \& Saúde Coletiva, v. 9, n. 1, p. 139-146, 2004.

COSTA, M. P. F. Ressucitação cardiopulmonar: aspectos da comunicação e do tempo. In: SILVA M. J. P. (Org.). Qual o tempo e o cuidado: humanizando os cuidados de Enfermagem. Centro Universitário São Camilo: Loyola, 2004. p. 111-122.

FLICK, U. Introdução à pesquisa qualitativa. 3. ed. Porto Alegre: Artmed, 2009.

FONTES, C. A. S; ALVIM, N. A. T. A relação humana no cuidado de enfermagem junto ao cliente com câncer submetido à terapia antineoplásica. Acta Paulista de Enfermagem, v. 21, n. 1, p. 77-783, 2008.

FRANCO, T. B.; MERHY, E. E. Trabalho, produção do cuidado e subjetividade em saúde: textos reunidos. 1. ed. São Paulo: Hucitec, 2013.

FURNARI, M. G. Il paziente Il medico nell'età della tecnicca. In: Il paziente Il medico nell'età della cura. Soveria Maneli: Rubbetino, 2005.

GUEDES, M. V. C.; HENRIQUES, A. C. P. T.; LIMA, M. M. N. Acolhimento em um serviço de emergência: percepção dos usuários. Revista Brasileira de Enfermagem, v. 66, n. 1, p. 31-37, 2013.

GOMES, C. H. R.; SILVA, P. V.; MOTA, F. F. Comunicação do diagnóstico do câncer: análise do comportamento médico. Revista Brasileira de Cancerologia, v. 55, n. 2, p. 139$143,2009$.

LEFÈVRE, F; LEFÈVRE, A. M. C. Discurso do Sujeito Coletivo: um novo enfoque em pesquisa qualitativa (desdobramentos). Caxias do Sul: EDUCS, 2005.

MERHY, E. E. Saúde: a cartografia do trabalho vivo em ato. 3. ed. São Paulo: Hucitec, 2007. 
MIYATA, H. et al. Disclosure preference regarding cancer diagnosis and prognosis: to tell or not tell? Journal Medicine Ethics, v. 31, p. 447-451, 2005.

MINAYO, M. C. Desafio do conhecimento: pesquisa qualitativa em saúde. 10 ed. São Paulo: Hucitec, 2007.

MIRANDA, J. M. Tecnologia autonomia e dignidade humana na área da saúde. In: SIQUEIRA, J. E.; PROTA, L. (Org.). Bioética: estudos e reflexão. Londrina-PR: EdUEL, 2000. p. 101-116.

OLIVEIRA, M. E. et al. Un ensayo sobre La comunicacion en los cuidados de la enfermaria utilizando los sentidos. Enfermaría Global, v. 8, p. 1-7, 2006.

ONOCKO CAMPOS, R. T.; CAMPOS, G. W. S. Construção de autonomia: o sujeito em questão. In: CAMPOS, G. W. S. (Org.). Tratado de saúde coletiva. São Paulo: Hucitec, 2006, v. 1, p. 669-714.

PESSINI, L. Humanização da dor e do sofrimento humanos na área da saúde. In: PESSINI, L. (Org.). Humanização e cuidados paliativos. São Paulo: Loyola, 2004. p. 12-30.

POTT, F. S. et al. Medicadas de conforto e comunicação nas ações de cuidado de enfermagem ao paciente crítico. Revista Brasileira de Enfermagem, v. 66, n. 2, p. 174-179, 2013.

PRIMO, W. Q. S. P.; GARRAFA, V. Análise ética da revelação do diagnóstico e tratamento em pacientes com câncer genital e mamário. Revista Associação Médica Brasileira, v. 56, n. 4, p. 397-402, 2010.

RENNÓ, C. S. N.; CAMPOS, C. J. G. Comunicação interpessoal: valorização pelo paciente oncológico em uma unidade de alta complexidade. Revista Mineira de Enfermagem, v. 18, n. 1, p. 106-115, 2013.

RODRIGUES, I. G. Cuidados paliativos: análise de conceito. 2004. 247 f. Dissertação (Mestrado em Enfermagem) - Escola de Enfermagem de Ribeirão Preto, São Paulo, 2004.

SILVA, C. H. et al. Not telling the truth in the patient- physician relationship. Bioethics, v. 17, p. 417-424, 2003.

SILVA, V. C. E. O impacto da revelação do diagnóstico de câncer na percepção do paciente. 2005. 219 f. Dissertação (Mestrado em Enfermagem) - Programa Interstitucional USP/ UEL/UNOPAR, São Paulo, 2005.

SILVA, H. B. Beneficência e paternalismo médico. Revista Brasileira de Saúde MaternoInfantil. v. 10, n. 2, p. 419-425, 2010.

SILVA, A. M. da.; SÁ, M. de C.; MIRANDA, L. Concepçôes de sujeito e autonomia na humanização em saúde: uma revisão bibliográfica das experiências na assistência hospitalar. Saúde e Sociedade, v. 22, n. 3, p. 840-852, 2013.

SOARES, N. V. A problematização dos direitos do cliente como desencadeadora da problematização dos direitos dos profissionais de enfermagem. 2000. 154f. Dissertação (Mestrado em Enfermagem) - Universidade Federal de Santa Catarina, Florianópolis (SC), 2000. 
TADDEO, P. da S. et al. Acesso, prática educativa e empoderamento de pacientes com doenças crônicas. Ciência \& Saúde Coletiva, v. 17, n. 11, p. 2913-2930, 2012.

TAVARES, J. S. C. Metáforas e significados do câncer de mama na perspectiva de cinco famílias afetadas. Cadernos de Saúde Pública, v. 21, n. 2, p. 426-35, 2005.

TORALLES-PEREIRA, M. L. et al. Comunicação em saúde: algumas reflexões a partir da percepção de pacientes acamados em uma enfermaria. Ciência \& Saúde Coletiva, v. 9, n. 4, p. 1013-1022, 2009.

TRINDADE, E. S. et al. O médico frente ao diagnóstico e prognóstico do câncer avançado. Revista Associação Médica Brasileira, v. 53, n. 1, p. 68-74, 2007.

ZABOLI, E. L. C. P.; SARTORIO, N. A. Bioética e enfermagem: uma interface no cuidado. O mundo da saúde, v. 30, n. 3, p. 382-97, 2006.

\section{Nota}

${ }^{1}$ M. R. Theobald realizou coleta e pré-análise dos dados e redigiu o artigo. M. L.de M. dos Santos realizou a análise dos dados e a revisão crítica do artigo. S. M. O. de Andrade analisou os dados quantitativos. A. D. De-Carli realizou a revisão crítica final do artigo e contribuiu com a problematização da discussão. 
Perceptions of the cancer patient about care Cancer triggers organic and emotional reactions, causing feelings, imbalances and internal conflicts. The study sought to identify the perceptions of the cancer patient about the professional care received. It is a qualitative study, constituting as a possibility of reflection on the care given to these patients, from the perspective of a humanistic approach. Twenty-five adult patients admitted to the Oncology Sector of a public institution, teaching and referral in the area, located in the Brazilian Center-West Region, where a semistructured interview was carried out, which had its script evaluated by professionals in the thematic area. After the data were collected, they were transcribed and systematized by the Collective Subject Discourse, and later they were confronted with the report of the Participating Systematic Observation. As results, the study identified a positive perception of the user about the care received, although the professional practice partially incorporates the recommendations recommended by the National Humanization Policy. It was concluded that it is necessary to invest efforts to enhance the incorporation of professional behaviors that prioritize humanized care, because their absence compromises therapeutic adherence, weakens the patient, and has an emotional impact on the individual.

> Keywords: humanization of care; Nursing, Oncology. 